\title{
15 \\ Defining and designing cost-effective agri-environment schemes
}

Dean Ansell

\section{Key lessons}

- Agri-environment schemes are often highly variable in both their economic cost and biodiversity benefit, creating the potential for significant inefficiencies in conservation expenditure.

- Evaluation of the cost-effectiveness of agri-environment schemes can identify opportunities to significantly improve the conservation gains with the available resources, however, such evaluations are uncommon.

- Simple economic evaluation tools can be applied by researchers or policymakers, using minimal economic data, to compare the costeffectiveness of agri-environment schemes at different scales and at stages through the implementation process.

\section{Introduction}

Over the past decade, concerns have been raised regarding the effectiveness of agri-environment schemes in conserving biodiversity. Studies have shown that the success of these schemes is highly variable, 
ranging from strong positive biodiversity benefits to neutral and even negative consequences. With global biodiversity declining dramatically and further threatened by agricultural intensification, a focus on the most effective strategies for conservation is critical. This issue is even more pertinent given that the funds available for biodiversity conservation are not sufficient to address the scale of the problem, and so agri-environment schemes are in competition with other conservation activities for limited resources. It is critical, therefore, that the costeffectiveness of agri-environment schemes are maximised to increase the biodiversity benefits obtained with available resources.

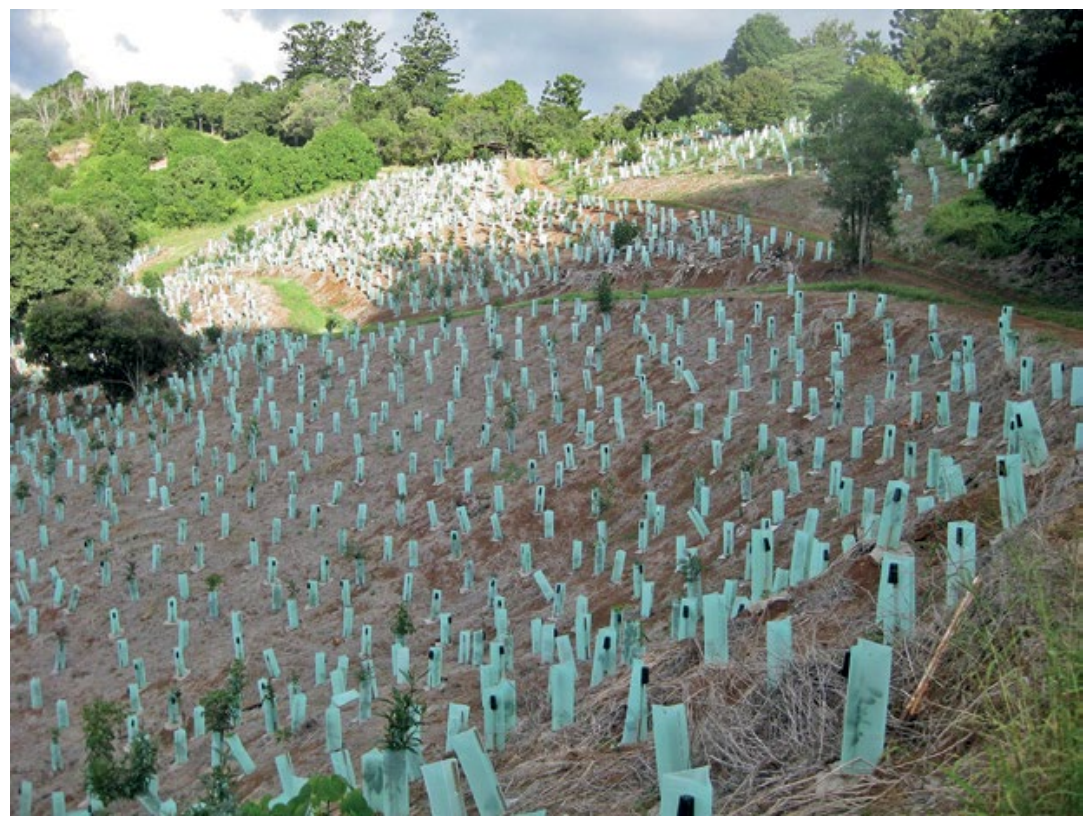

Figure 15.1: The cost-effectiveness of agri-environment schemes can be influenced by many factors, from the location of sites to the specific conservation techniques used.

Source: Photo by Brisbane City Council available at www.flickr.com/photos/brisbanecity council/7926277216 under a Creative Commons Attribution 2.0.

Typically, evaluation of agri-environment schemes has been dominated by ecological or economic perspectives (Uthes and Matzdorf 2013). There has been comparatively little attention given to the costeffectiveness of these schemes. A recent review of 239 studies on the effectiveness of agri-environment schemes around the world found that fewer than 15 per cent considered economic costs in the evaluation 
(Ansell et al. in preparation). This is surprising, given the scale of the public expenditure in agri-environment schemes and increasing recognition of the biodiversity benefits that can be achieved through consideration of economic costs in the conservation planning process (see Chapter 17 by Fiona Gibson and colleagues).

This chapter explores issues of the effectiveness and efficiency of agri-environment schemes, first defining cost-effectiveness in the context of such schemes, and providing an overview of common evaluation approaches. I conclude with a discussion on the outcomes of previous evaluations of the cost-effectiveness of agri-environment schemes, highlighting key aspects relevant to the design and implementation of agri-environment schemes in Australia.

\section{What is cost-effectiveness?}

Cost-effectiveness refers to the relative efficiency of an action in achieving an outcome. It can be expressed as the total cost of producing a single unit of benefit (i.e. cost/benefit), or alternatively as the total benefit produced per unit of cost (i.e. benefit/cost) (Wätzold and Schwerdtner 2005). Both approaches generate a ratio, referred to as the cost-effectiveness ratio or benefit-cost ratio, which forms the basis of a cost-effectiveness analysis. The ratio allows one to compare the efficiency of alternative actions. Note that while I focus here on evaluation approaches involving non-monetary measures of conservation benefit, as opposed to methods that assign a monetary value to the effectiveness measure, the concepts discussed apply generally across both approaches.

When applied to the evaluation of biodiversity benefits of agri-environment schemes, we can take cost-effectiveness as the biodiversity benefit produced per unit of cost (or, alternatively, cost per biodiversity unit). Comparison of the cost-effectiveness of different agri-environment schemes allows identification of those that provide the greatest biodiversity benefit per dollar spent.

Variation in both the economic costs and effectiveness of conservation activities give rise to differences in the cost-effectiveness of agri-environment schemes (Wätzold and Schwerdtner 2005). Agricultural ventures are rarely static in time and space, with farming practices, production intensity, and commodity choice varying according to various external market factors (Barraquand 
and Martinet 2011). This gives rise to significant variation in the opportunity costs of conservation on farmland at multiple spatial and temporal scales. Similarly, the effectiveness of agri-environment schemes in conserving biodiversity is highly variable, both temporally and spatially, and is influenced by factors at the field or farm scale (e.g. site size, management history) as well as at the landscape or regional scales (e.g. surrounding land use, connectivity, climate) (e.g. Concepción and Díaz 2011). Effectiveness also varies between taxa, with some schemes providing positive conservation outcomes for some taxa while providing no benefit or even negative outcomes for other taxa (Kleijn et al. 2006).

Complex interdependencies also exist between the effectiveness and cost of conservation activities in agri-environment schemes. For example, the overall cost of an agri-environment scheme is strongly influenced by the configuration (i.e. size and shape) of the particular field, with larger sites incurring a higher opportunity cost to the landholder, in turn requiring an increased payment rate, and often requiring increased materials. This can also influence biodiversity outcomes, with factors such as field size and shape shown to be important determinants of conservation effectiveness (Conover et al. 2011). This variation in costs and effectiveness, and the complex interactions between the two, create the potential for significant inefficiencies in conservation expenditure. Simple evaluation of the cost-effectiveness of agri-environment schemes can reveal factors driving conservation efficiency and identify opportunities to maximise the conservation benefits from investments.

\section{Cost-effectiveness in practice}

A critical step in the evaluation of the cost-effectiveness of agri-environment expenditure is the assessment of the costs of the scheme itself. The costs associated with agri-environment schemes can be categorised as acquisition (e.g. land rent), management (e.g. site establishment, maintenance), transaction (e.g. negotiation, legal), and opportunity costs (e.g. forgone agricultural production) (Naidoo and Ricketts 2006). Consideration of the latter is particularly critical, as it can influence the design, uptake, and ultimately the effectiveness of biodiversity conservation in farmland, but is often omitted from project evaluations. 
Evaluations can use realised or actual costs (Klimek et al. 2008), or estimated costs based on market rates, averages, or surrogates (Bamière et al. 2013). While evaluation based on actual costs provides improved accuracy, such information is not always readily available. Naidoo and Ricketts (2006) provide an overview of approaches for the estimation of common cost components of biodiversity conservation. Evaluations should attempt to take account of the full costs (and benefits) of agri-environment schemes (Bamière et al. 2013).

The other key component in the evaluation of cost-effectiveness is obviously the measure of the benefit or the effectiveness of conservation. As the numerator in most cost-effectiveness equations, it can strongly influence the outcomes of the evaluation and therefore careful selection is critical. Evaluation can use direct or field-based measures of effectiveness such as changes in single species abundance or density, or, alternatively, look at measures of community diversity (e.g. Ulber et al. 2011). Measures of habitat area or quality have also been used, either as direct measures of agri-environment schemes effectiveness (e.g. Wynn 2002), or as surrogate measures of broader biodiversity benefits (e.g. Hansen 2007). Thompson et al. (1999) use area of land enrolled in the particular agri-environment schemes under review as a proxy for effectiveness.

Many evaluations, particularly those carried out at the planning stages of agri-environment schemes (i.e. ex ante, see below) are based on modelled or predicted outcomes as measures of effectiveness. For example, Bamière et al. (2013) use spatial modelling to assess the efficiency of agri-environment policies by focusing on the spatial configuration of farm land for habitat conservation, specifically aiming for a random mosaic of sites, noting that such a configuration is more effective in the conservation of certain species, such as their model species, the little bustard, which depends on a mosaic of agricultural land use (i.e. crops, grassland).

Except where the particular objectives of the agri-environment schemes or research question dictates the use of a specific measure of effectiveness - for example, changes in the abundance of a species or in the area of a certain habitat - the researcher will be faced with the difficult task of selecting a suitable measure to capture, to the extent possible, the extent of the biodiversity benefits resulting from the scheme. In such cases, multiple benefits can be captured in 
a metric that can then be used in economic analysis. Multi-criteria analysis approaches have also been used to combine multiple disparate environmental values into single measures (e.g. Hajkowicz and Collins 2009). (In Chapter 17, Fiona Gibson and David Pannell discuss the consequences of using the wrong metric, while in Chapter 20 Phil Gibbons provides an overview of the development of metrics.)

Irrespective of the particular effectiveness measure selected, careful consideration should be given to the means of collecting that information and its expression within the cost-effectiveness evaluation. Experimental design is critical in the assessment of cost-effectiveness. Failure to account for conservation status in the absence of the treatment (i.e. control or counterfactual) can lead to inflated measures of benefit and cost-effectiveness (a topic discussed by Duncan and Reich in Chapter 19). Kleijn and Sutherland (2003) found significant shortcomings in the design of studies evaluating the effectiveness of European agri-environment schemes, stemming largely from either poor, or absent, controls. The authors propose a number of remedies, including the use of baseline data, comparison of trends in treatments and controls, and use of carefully selected treatment and control site pairs. Of particular importance is the use of conservation gain (i.e. the difference in the biodiversity value between the treatment and control) as the measure of conservation benefit, rather than absolute values. This provides a more accurate measure of the benefit that has been purchased with the investment and controls for differences in the baseline condition or value (Maron et al. 2013).

Cost-effectiveness can be considered at a variety of scales in the agri-environment schemes process. For example, we can consider the efficiency of different agri-environment policies in achieving environmental outcomes at a broad scale. Bamière et al. (2013) use a modelling approach to compare the cost-efficiency of three different agri-environment schemes, each using a different incentive mechanism, in achieving a specific objective for the conservation of little bustard habitat in French farmland. In contrast, we can compare the cost-effectiveness of specific measures in achieving their biodiversity objectives. Wilson et al. (2007) evaluate the costeffectiveness of two different conservation activities (a low cost habitat preservation option and a high cost habitat restoration option) aimed at improving wading bird populations in southern England under the Environmentally Sensitive Areas scheme. They find that, despite the 
habitat restoration measure costing 50 per cent more per hectare than the habitat preservation measure, the return on investment from the higher cost option, measured as cost per breeding pair of waders, was more than 90 per cent higher than the low-cost option. This provides a strong example of the power of a simple cost-effectiveness analysis in comparing the efficiency of different conservation activities. The choice of scale for evaluation should be appropriate for the research or policy question, and will influence the detail or resolution of the ecological and economic information required in the evaluation.

\section{Box 15.1: Before, during and after - timing of AES evaluation.}

We can also consider the cost-effectiveness of agri-environment schemes at different time stages throughout the process. Evaluations carried out prior to the implementation are referred to as ex ante evaluations and can provide important input into scheme design and implementation. Such evaluations provide the opportunity to optimise the efficiency and biodiversity benefits of agri-environment schemes investments. Van der Horst (2007) assessed the efficiency gains from spatial targeting of a woodland agri-environment schemes and found biodiversity gains of 1.6-2.1 times greater than that achieved through the untargeted scheme. White and Sadler (2011) achieve a 17 per cent budget saving through the use of conservation contracts based on variable payments tailored to outcomes achieved on individual enrolled farms compared to traditional fixed-price contracts.

Evaluations can also be carried out during (in media res) or upon completion (ex post) of a scheme. In contrast to ex ante evaluations, which typically involve modelling of predicted biodiversity benefits and costs, such evaluations can use realised benefits and actual costs as inputs, provide a retrospective assessment of the efficiency of expenditure, and identify improvements for future programs. Both ex ante and ex post evaluations provide useful information about the biodiversity benefits of agri-environment schemes. While the use of predicted biodiversity benefit and cost information in ex ante evaluations may provide less accurate information than approaches using realised benefits and actual costs (i.e. ex ante evaluations) (Boardman et al. 2010), conducting evaluations at this stage may improve the efficiency of an agri-environment scheme before funding is expensed. In contrast, ex post evaluations, while providing information to improve the efficiency of future expenditure, can be hampered by limited availability of financial data and methodological issues around the measurement of biodiversity gains.

Despite these shortcomings, both approaches can contribute to the refinement of agri-environment schemes and increase the biodiversity gains and efficiency of agri-environment expenditure. Ultimately, the choice of evaluation approach may be determined by financial and logistical constraints. 


\section{Lessons learnt}

While we may be tempted to think that the more we spend on agri-environment schemes, the better the biodiversity outcomes, evaluations reveal the relationship between the two is anything but straightforward. While some studies support this concept by demonstrating higher levels of conservation benefit with increasing expenditure (Barraquand and Martinet 2011; Wilson et al. 2007), others reveal more complex relationships. For example, in an ex post evaluation of the Scottish Woodland Grants Scheme, which aimed to improve priority habitats in farmland, Wynn (2002) found wide variation in cost, biodiversity benefit, and cost-effectiveness across different farm types.

Shining a light on the economics of biodiversity conservation in farming landscapes can reveal some ugly truths that would otherwise not be uncovered by traditional ecological evaluations. Examples include the prevalence of significant windfall effects in agri-environment schemes, where farmers receive payments for environmental services or biodiversity outcomes that would have occurred regardless of whether the scheme was implemented (Chabé-Ferret and Subervie 2013; Sierra and Russman 2006; Ulber et al. 2011), and a reliance on agri-environment schemes payments for farm income (Pietzsch et al. 2013). Recent modelling of the cost-effectiveness of habitat restoration on Australian farmland suggests that our current focus on restoring remnant habitats, as is the focus of the Australian Government's largest agri-environmental scheme, the Environmental Stewardship Scheme (see Chapter 3 by Burns and colleagues), is suboptimal, with revegetation of cleared areas demonstrating higher biodiversity gains per dollar spent (Jellinek et al. 2014).

While it is important that seemingly negative research outcomes such as these be evaluated and communicated, there is a potential risk of perverse conservation outcomes where seemingly adverse economic results drive policy decisions (i.e. cancellation of programs) at the expense of important biodiversity values or priorities. The challenge is in maintaining perspective in evaluating the costeffectiveness of agri-environment schemes and assessing the outcomes of such evaluations in the context of the scheme's overall biodiversity objectives. 
Evaluation can also provide important lessons for the design of future conservation programs. Many agri-environment schemes use a simple incentive system, where payments to farmers are based on fixed rates per hectare. Such approaches are relatively easy to administer, but risk significant inefficiency though overcompensation of farmers otherwise willing to accept a lower price for conservation (Klimek et al. 2008). This can also exacerbate the problem of marginal, low productivity areas dominating the enrolled land as farmers seek to minimise opportunity cost and maximise returns from enrolment (Bamière et al. 2013).

Several studies demonstrate the efficiency gains that can be achieved through more complex delivery mechanisms, such as auction-based and payment-by-results type systems (e.g. Barraquand and Martinet 2011; Thompson et al. 1999; Klimek et al. 2008). Stoneham et al. (2003) compared the outcomes of a pilot auction for the Victorian BushTender scheme and found such an approach would achieve the same biodiversity outcomes at a cost seven times less than those achieved using a fixed-rate incentive payment. The increased efficiency of these approaches, however, must be balanced against the higher administrative or transaction costs associated with their implementation (Klimek et al. 2008; White and Sadler 2011).

\section{Conclusion}

It is unfortunate that better use is not made of simple tools of economic evaluation in the planning and assessment of conservation expenditure in agricultural land. By focusing only on biological or ecological aspects in our evaluations, we miss opportunities to significantly increase the biodiversity benefits that can be achieved with the limited funding available. As demands to feed a growing population place even greater pressure on biodiversity in agricultural landscapes and the conservation purse strings tighten, maximising the efficiency of our conservation dollar becomes even more critical. Understanding the cost-effectiveness of our agri-environment investments is a critical step towards meeting this aim. 


\section{References}

Ansell, D., D. Freudenberger, N. Munro and P. Gibbons (in preparation) The cost-effectiveness of agri-environment schemes: a systematic review.

Bamière, L., M. David and V. Vermont (2013) 'Agri-environmental policies for biodiversity when the spatial pattern of the reserve matters', Ecological Economics 85: 97-104.

Barraquand, F. and V. Martinet (2011) 'Biological conservation in dynamic agricultural landscapes: Effectiveness of public policies and trade-offs with agricultural production', Ecological Economics 70(5): 910-20.

Boardman, A., et al. (2010) Cost-benefit analysis, fourth edition, Prentice Hall, Upper Saddle River, NJ.

Chabé-Ferret, S. and J. Subervie (2013) 'How much green for the buck?: Estimating additional and windfall effects of French agroenvironmental schemes by DID-matching', Journal of Environmental Economics and Management 65(1): 12-27.

Concepción, E.D. and M. Díaz (2011) 'Field, landscape and regional effects of farmland management on specialist open-land birds: Does body size matter?' Agriculture, Ecosystems and Environment 142: 303-10.

Conover, R.R., S.J. Dinsmore and L.W. Burger (2011) 'Effects of conservation practices on bird nest density and survival in intensive agriculture', Agriculture, Ecosystems and Environment 141(1-2): 126-32.

Hajkowicz, S. and K. Collins (2009) 'Measuring the benefits of environmental stewardship in rural landscapes', Landscape and Urban Planning 93(2): 93-102.

Hansen, L. (2007) 'Conservation reserve program: Environmental benefits update', Agricultural and Resource Economics Review 2: 267-80. 
Herzog, F. et al. (2005) 'Effect of ecological compensation areas on floristic and breeding bird diversity in Swiss agricultural landscapes', Agriculture, Ecosystems and Environment 108(3): 189-204.

Hinsley, S.H.A. et al. (2010) 'Testing agri-environment delivery for farmland birds at the farm scale: The Hillesden experiment', Ibis 152: $500-14$.

Jellinek, S., L. Rumpff, D.A. Driscoll, K.M. Parris and B.A. Wintle (2014) 'Modelling the benefits of habitat restoration in socioecological systems', Biological Conservation 169: 60-7.

Kleijn, D., R. Baquero and Y. Clough (2006) 'Mixed biodiversity benefits of agri-environment schemes in five European countries', Ecology Letters, 9(3): 243-54.

Kleijn, D. and W.J. Sutherland (2003) 'How effective are European agrienvironment schemes in conserving and promoting biodiversity?', Journal of Applied Ecology 40(6): 947-969.

Klimek, S. et al. (2008) 'Rewarding farmers for delivering vascular plant diversity in managed grasslands: A transdisciplinary casestudy approach', Biological Conservation 141(11): 2888-97.

Knop, E. and D. Kleijn (2006) 'Effectiveness of the Swiss agrienvironment scheme in promoting biodiversity', Journal of Applied Ecology 43: 120-7.

Konvicka, M. et al. (2008) ‘How too much care kills species: Grassland reserves, agri-environmental schemes and extinction of Colias myrmidone (Lepidoptera : Pieridae) from its former stronghold', Journal of Insect Conservation 12(5): 519-25.

Maron, M., J. Rhodes and P. Gibbons (2013) 'Calculating the benefit of conservation actions', Conservation Letters 6(5): 359-67.

McCarthy, D., et al. (2012) 'Financial costs of meeting global biodiversity conservation targets: current spending and unmet needs', Science 338: 946-9.

Naidoo, R. and T.H. Ricketts (2006) 'Mapping the economic costs and benefits of conservation' PLoS Biology 4(11): e360. 
Pietzsch, D., et al. (2013) 'Low-intensity husbandry as a cost-efficient way to preserve dry grasslands', Landscape Research 38(4): 523-39.

Sierra, R. and E. Russman (2006) 'On the efficiency of environmental service payments: A forest conservation assessment in the Osa Peninsula, Costa Rica', Ecological Economics 59: 131-41.

Stoneham, G., V. Chaudhri, A. Ha and L. Strappazzon (2003) 'Auctions for conservation contracts: An empirical examination of Victoria's BushTender trial', Australian Journal of Agricultural and Resource Economics 47: 477-500. DOI:10.1111/j.1467-8489.2003.

Thompson, S., A. Larcom and J.T. Lee (1999) 'Restoring and enhancing rare and threatened habitats under agri-environment agreements: A case study of the Chiltern Hills area of outstanding natural beauty, UK', Land Use Policy 16(2): 93-105.

Ulber, L., et al. (2011) 'Implementing and evaluating the effectiveness of a payment scheme for environmental services from agricultural land', Environmental Conservation 38(4): 464-72.

Uthes, S. and B. Matzdorf (2013) 'Studies on agri-environmental measures: A survey of the literature', Environmental management 51(1): 251-66.

Van der Horst, D. (2007) 'Assessing the efficiency gains of improved spatial targeting of policy interventions: The example of an agrienvironmental scheme', Journal of Environmental Management 85: 1076-87.

Wätzold, F. and K. Schwerdtner (2005) 'Why be wasteful when preserving a valuable resource?: A review article on the costeffectiveness of European biodiversity conservation policy', Biological Conservation 123: 327-38.

White, B. and R. Sadler (2011) 'Optimal conservation investment for a biodiversity-rich agricultural landscape', Australian Journal of Agricultural and Resource Economics 56: 1-21.

Whittingham, M.J. (2007) 'Will agri-environment schemes deliver substantial biodiversity gain, and if not why not?', Journal of Applied Ecology 44: 1-5. 
Wilson, A., J. Vickery and C. Pendlebury (2007) 'Agri-environment schemes as a tool for reversing declining populations of grassland waders: Mixed benefits from environmentally sensitive areas in England', Biological Conservation 136(1): 128-35.

Wynn, G. (2002) 'The cost-effectiveness of biodiversity management: A comparison of farm types in extensively farmed areas of Scotland', Journal of Environmental Planning and Management 45(6): 37-41. 
This text is taken from Learning from agri-environment schemes in Australia: Investing in biodiversity and other ecosystem services on farms, edited by Dean Ansell, Fiona Gibson and David Salt, published 2016 by ANU Press, The Australian National University, Canberra, Australia. 